\title{
Faktor-Faktor yang Mempengaruh Siswa SLTA dalam Memilih Perguruan Tinggi di Kabupaten Batang Hari (Studi Kasus Pada STAI dan STIE-GK Muara Bulian)
}

\author{
Ahmad Fithoni, Atang Priyatna \\ STIE Graha Karya Muara Bulian, Jambi, Indonesia
}

\begin{abstract}
This study aims to find out and analyze the factors that influence the decision of high school students in choosing universities in Batang Hari Regency. The object of research is STAI and STIE-GK Muara Bulian. This research is descriptive quantitative with the number of respondents as many as 75 students for each college which is the object of research registered in the 2018/2019 academic year. This type of research is descriptive qualitative research that aims to determine whether there is an influence or relationship between two or more variables with the analysis tools used include Partial Test ( $t$ test), Simultaneous Test (Test F), and Determination Coefficient Test $\left(R^{2}\right)$. The results of the study show that the independent variables include Study Program variables (X1), Accreditation Status (X2), Facilities (X3) and Costs (X4) on Student Decisions (Y). For STAI Muara Bulian, only Accreditation variables have a partial influence on student decisions and even then it is not significant. For STIE-GK Muara Bulian, it is known that all independent variables have a partial and significant influence on the decisions of high school students to enter. Judging from the $F$ test, it is known that the independent variables simultaneously have an influence on the dependent variable in having a college in Batang Hari Regency. The test results of the coefficient of determination for STAI Muara Bulian amounted to 88.9\% and for STIE-GK Muara Bulian at 95.3\% while the remaining respectively $11.1 \%$ and $4.7 \%$ were influenced by other factors not included in the research variable.
\end{abstract}

Keywords: Study Program; Accreditation; Facilities; Fees and Student Decisions

DOI: 10.33087 /ekonomis.v3i1.60

\section{PENDAHULUAN}

Pendidikan merupakan aspek yang sangat penting bagi perkembangan sumber daya manusia, sebab pendidikan merupakan wahana atau salah satu instrumen yang digunakan bukan saja membebaskan manusia dari keterbelakangan, melainkan juga dari kebodohan dan kemiskinan (Adisetiawan, 2017). Pendidikan diyakini mampu menanamkan kapasitas baru bagi semua orang untuk mempelajari pengetahuan dan keterampilan baru sehingga dapat diperoleh manusia produktif. Selanjutnya Adisetiawan (2017) mengungkapkan bahwa Pendidikan adalah segala kegiatan pembelajaran yang berlangsung sepanjang zaman dalam segala situasi kegiatan kehidupan. Pendidikan berlangsung disegala jenis, bentuk, dan tingkat lingkungan hidup, yang kemudian mendorong pertumbuhan segala potensi yang ada didalam diri individu . Di sisi lain, pendidikan dipercayai sebagai wahana perluasan akses. Pendidikan mempunyai fungsi yang harus diperhatikan seperti dapat dilihat pada UU No. 22 tahun 2003 pasal 3 yang menyatakan bahwa pendidikan nasional berfungsi mengembangkan kemampuan dan membentuk watak serta peradaban bangsa yang bermartabat dalam rangka mencerdaskan kehidupan bangsa, bertujuan untuk berkembangnya potensi peserta didik agar menjadi manusia yang beriman dan bertaqwa pada Tuhan Yang Maha Esa, beraklaq mulia, sehat berilmu, cakap, kreatif, mandiri dan menjadi warga yang demokratis dan bertanggungjawab.

Semakin ketatnya persaingan di era global dan tuntunan persaingan di dunia kerja, sangat dibutuhkan sumber daya manusia yang memiliki ketrampilan dan mampu membangun dirinya sendiri serta bersama-sama bertanggung jawab atas pembangunan bangsa. Kemajuan suatu bangsa dimasa akan datang sangatlah tergantung pada mutu pendidikan generasi muda saat ini, karena pemuda adalah ujung tombak dari kesuksesan suatu negara (Adisetiawan, 2016). Pemerintah secara terus menerus berusaha semaksimal mungkin untuk meningkatkan kualitas pendidikan di Indonesia, dengan upaya sedemikian rupa yang bertujuan agar pendidikan di Indonesia ini terlihat lebih baik, karena Pendidikan Nasional ini ingin menciptakan manusia yang semakin cerdas, terampil, berbudi pekerti yang luhur serta bertakwa kepada Tuhan Yang Maha Esa. Hal ini ditegaskan dalam Pendidikan Nasional Indonesia yaitu kualitas sumber daya manusia merupakan hal yang terpenting bagi kemajuan negara Indonesia. Selain itu juga menjadi salah satu faktor kunci keberhasilan dalam era perdagangan bebas, penguasaan ilmu pengetahuan, dan tekonologi. Kualitas sumber daya manusia hanya dapat diperoleh melalui jalur pendidikan. Sebagai langkah implementasi awal pemerintah pada tahun 1994 yang lalu telah menetapkan wajib belajar 9 tahun. Peningkatan sumber daya manusia akan menjadi hal yang terpenting bagi generasi muda yang menjadi tonggak kehidupan majunya negara Indonesia, karena bagaimanapun juga generasi muda 
merupakan generasi penerus bangsa yang nantinya akan membawa bangsa menuju kemajuan dimasa yang akan datang.

Bagi siswa yang mengeyam pendidikan di sekolah menengah atas (SMA), menjadi suatu alasan siswa untuk melanjutkan studi ke jenjang pendidikan yang lebih tinggi, yaitu perguruan tinggi (Adisetiawan, 2016). UU No. 20 tahun 2003 pasal 19 ayat 1 yang menyatakan bahwa Perguruan tinggi merupakan jenjang pendidikan setelah pendidikan menengah mencakup program pendidikan diploma, sarjana, magister, spesialis, dan doktor yang diselenggarakan oleh perguruan tinggi. Perguruan tinggi yang ada di Indonesia dapat berbentuk Politeknik, Sekolah Tinggi, Akademik, Universitas, dan Institut. Perguruan tinggi adalah satuan pendidikan penyelenggara pendidikan tinggi. Peserta didik perguruan tinggi disebut mahasiswa, sedangkan tenaga pendidik perguruan tinggi disebut dosen. Perguruan tinggi juga dapat diartikan dengan suatu lembaga pendidikan yang menyelenggarakan pendidikan dan berbagai macam keahlian, misalnya : bidang pendidikan, ekonomi, hukum, psikologi, teknik, kesehatan dan lain-lain yang sesuai dengan Undang-undang No. 20 tahun 2003 menetapkan perguruan tinggi berupa akademik, politeknik, sekolah tinggi, institut atau universitas yang ditetapkan oleh pemerintah. Menjejangkan karir di perguruan tinggi, akan mematangkan siswa baik didalam memperoleh ilmu, berperilaku dan cara berfikir. Cara berfikir yang rasional syarat akan pengujian yang ilmiah, serta mampu dipertanggung jawabkan kebenarannya, merupakan ciri khas yang dimiliki oleh mahasiswa. Mahasiswa selalu menggunakan fikirannya secara rasional jika memecahkan suatu masalah. Sedangkan matangnya suatu ilmu yang ditempuh mahasiswa diperguruan tinggi, akan menjadikan mahasiswa berperilaku yang baik pula. Pendidikan memang merupakan salah satu faktor yang tidak dapat dipisahkan dari kehidupan seseorang, baik dalam keluarga, masyarakat dan bangsa.

Pernyataan diatas, dapat disimpulkan pendidikan merupakan sistem proses perubahan menuju pendewasaan, pencerdasan, dan pematangan diri. Dewasa dalam hal perkembangan badan cerdas dalam hal perkembangan jiwa, dan matang dalam perilaku.Pada dasarnya pendidikan adalah wajib bagi siapa saja, kapan saja, dan dimana saja, karena menjadi dewasa, cerdas, dan matang adalah hak asasi manusia pada umumnya.Pendidikan memang harus berlangsung disetiap jenis, bentuk, dan tingkat lingkungan, mulai dari lingkungan individual, sosial keluarga, lingkungan masyarakat luas, dan berlangsung disepanjang waktu. Jadi, kegiatan pendidikan berlangsung dengan memadati setiap jengkal ruang lingkungan kehidupan. Undang-Undang Dasar Negara Republik Indonesia Tahun 1945 pasal 31 ayat (1) menyebutkan bahwa setiap warga negara berhak mendapatkan pendidikan, dan ayat (3) menegaskan bahwa pemerintah mengusahakan dan menyelenggarakansatu sistem pendidikan nasional yang meningkatkan keimanan dan ketaqwaan sertaakhlak mulia dalam rangka mencerdaskan kehidupan bangsa yang diatur dengan Undang-Undang. Undang-Undang Nomor 20 Tahun 2003 menyatakan bahwa sistem Pendidikan Nasional memberikan dasar hukum untuk membangun pendidikan nasional dengan menerapkan prinsip Demokrasi, desentralisasi, otonomi, keadilan dan menjunjung tinggi hak asasi manusia. Penerapan ketentuandalam undang-undang ini diharapkan dapat mendukung segala upaya untukmemecahkan masalah pendidikan, guna memberikan sumbangan yang signifikanterhadap masalah-masalah makro bangsa Indonesia. Untuk itu, seluruh komponen bangsa wajib mencerdaskan kehidupanmasyarakat yang merupakan tujuan bangsa Indonesia, sehingga memberikankesempatan terhadap seluruh komponen masyarakat berhak untuk mendapatkanpendidikan yang lebih baik guna menciptakan sumber daya manusia yangberkualitas dan bertaqwa.Dalam kerangka globalisasi, penyiapan pendidikan perlu disinergikandengan tuntutan kompetisi. Karena itu dimensi daya saing dalam sumber dayamanusia kelak menjadi faktor penting sehingga upaya memacu kualitas sumberdaya manusia melalui pendidikan merupakan tuntutan yang harus dikedepankan.

Untuk itu, lembaga pendidikan tinggi dituntut untuk mampu meningkatkan kualitas lulusannya agar mampu bersaing dengan tenaga baik dari dalam maupun luar negeri. Hal ini bukan hanya merupakan tanggung jawab perguruan tinggi negeri namun juga lembaga-lembaga pendidikan tinggi swasta, karena mengingat adanya batas daya tampung pada perguruan tinggi 
negeri. Dengan demikian, peranan pihak swasta di seluruh Indonesia sangat diharapkan dalam penciptaan kualitas sumber daya manusia yang handal. Dalam upaya pengembangan lembaga pendidikan, merupakan suatu tantangan untuk menghasilkan sumber daya manusia yang handal, berkualitas dan berdaya saing tinggi. Sebuah perguruan tinggi harus mampu mengetahui apa yang penting untuk para mahasiswa, memberikan informasi kepada para mahasiswa bahwa apa yang akan mereka berikan berguna untuk mahasiswa, dan kemudian memberikan apa yang telah mereka janjikan. Terdapat beberapa faktor yang menjadi daya tarik suatu perguruan tinggi baik secara internal maupun eksternal perguruan tinggi tersebut, sehingga mahasiswa memutuskan memilih perguruan tinggi tersebut untuk melanjutkan pendidikan. Dilihat dari faktor internal dapat meliputi minat, persepsi yang lebih kepada keinginan individu dari seorang siswa, sedangkan dilihat dari faktor eksternal dan biasanya menjadi pertimbangan lebih bagi seseorang (siswa) untuk menentukan pilihannya meliputi : Program studi yang diselenggarakan oleh suatu perguruan tinggi, status akreditasi perguruan tinggi, fasilitas yang dimiliki seperti perpustakaan, ruang kuliah maupun tampilan dari suatu perguruan tinggi serta biaya yang dikenakan kepada mahasiswa baik untuk masuk maupun biaya semester dan biaya-biaya lainnya (Adisetiawan, 2017).

\section{METODE}

Jenis penelitian yang digunakan adalah dengan menggunakan metode penelitian deskriptif kuantitatif. Jenis data yang diperoleh yaitu berdasarkan studi keustakaan dengan mengumpulkan data yang diperlukan, (Sugiyono, 2011) tentang jenis data yang biasanya digunakan untuk penelitian terdiri atas data kualitatif dan data kuantitatif. Sedangkan sumber data dalam penelitian ini bersumber dari data Primer dan data sekunder. Metode pengumpulan data yang digunakan pada penelitian ini terdiri atas : a) Library Research; dan b) Field Risearch. Metode pengumpulan data dengan cara melihat langsung kelapangan. Dalam penelitian ini penulis melakukan penelitian langsung kepada objek yang diteliti dengan cara: 1). Observasi, 2). Interview dan 3). Penyebaran angket, dengan skala likert dengan interval 1-5. Yang diukur dengan lima tingkatan prefensi jawaban yang masing-masing Sangat Tidak Setuju, Tidak Setuju, Ragu-ragu, Setuju sampai dengan Sangat Setuju.

Tabel 1. Indeks Penilaian Jawaban Responden. Nilai Indeks Keterangan Penilaian

$1,00-1,80$
$1,80-2,60$
$2,60-3,40$
$3,40-4,20$
$4,20-5,00$

Sangat Tidak Baik Tidak Baik Cukup Baik

$4,20-5,00$ Sangat Baik

\section{Populasi dan Sampel}

Populasi adalah mahasiswa dan mahasiswi yang terdaftar di STAI dan STIE-GK Muara Bulian pada Semester I, III dan V pada tahun akademik 2018/2019. Metode pengambilan sampel yang digunakan adalah Aksidental Sampling yaitu tehnik penentuan sampel berdasarkan kreteria atau pertimbangan tertentu (Usman rianse dan Abdi, 2012). Dikarenakan populasi dianggap homogen maka peneliti hanya mengambil sebagian kecil dari populasi yang ada yaitu sebanyak 75 orang dari masing-masing perguruan tinggi. Metode analisis data merupakan suatu metode yang digunakan untuk mengelola hasil penelitian guna memperoleh suatu instrument atau kesimpulan. Adapun metode analisis data yang digunakan dalam penelitian ini adalah: uji validitas, uji reliabilitas, regresi Linear berganda (Uji F), uji hipotesis parsial (Uji t), uji t yaitu untuk menguji kemaknaan koefisien regresi parsial jika $t$ hitung $>t$ table. Uji signifikansi digunakan untuk mengetahui apakah variabel independen (X) berpengaruh dan signifikan secara farsial atau tidak terhadap variabel dependen (Y), serta digunakan unuk mengetahui hipotesis ditolak atau diterima. Signifikansi berarti pengaruh yang terjadi dapat berlaku untuk populasi (dapat digeneralisasikan). Kriteria penolakan dan 
penerimaan hipotesis adalah jika nilai $t_{\text {hitung }}>t$ table dan nilai signifikansi $<0,05$, maka hipotesis nol $\left(\mathrm{H}_{0}\right)$ ditolak dan hipotesis alternative $\left(\mathrm{H}_{\mathrm{a}}\right)$ diterima; dan uji Hipotesis Simultan (Uji $\mathrm{F}$ ), menurut Santoso (2001) uji ini digunakan untuk mengetahui pengaruh bersama-sama variabel bebas terhadap variabel terikat. Dimana $\mathrm{F}_{\text {hitung }}>\mathrm{F}_{\text {tabel }}$, maka $\mathrm{H}_{0}$ ditolak atau secara bersama sama variabel independen tidak dapat menerangkan variabel dependen secara serentak. Sebaliknya apabila $F_{\text {hitung }}<\mathrm{F}_{\text {tabel }}$, maka $\mathrm{H}_{0}$ diterima atau secara bersama- sama variabel independen memilliki pengaruh terhadap variabel dependen. Untuk mengetahui signifikan atau tidak pengaruh bersama-sama variabel independen terhadap variabel dependen maka digunakan probability sebesar $5 \%(a=0,05)$. Koefisien Determinasi $\left(\mathrm{R}^{2}\right)$ pada intinya mengukur seberapa jauh kemampuan model dalam menerangkan variasi variabel dependen (Ghozali, 2011).Nilai koefisien determinasi adalah antara nol dan satu. Nilai $\mathrm{R}^{2}$ yang terkecil berarti kemampuan variabel-variabel independen dalam menjelaskan variasi variabel dependen sangat terbatas.Nilai yang mendekati satu berarti variabel-variabel independen memberikan hampirsemua informasi yang dibutuhkan untuk memprediksi variasi variabel dependen.

\section{HASIL \\ Faktor-Faktor yang Mempengaruhi Keputusan Siswa dalam memilih Perguruan Tinggi di Kabupaten Batang Hari. Faktor Program Studi}

Hasil pengolahan data, diketahui variabel program studi STAI memiliki nilai rata-rata indeks sebesar 3,35 sedangkan nilai indeks rata-rata untuk STIE-GK sebesar 3,53. Yang menunjukan bahwa mahasiswa berpendapat bahwa program studi yang terdapat pada STAI berada dalam kategori Cukup sedangkan untuk Progran Studi pada STIE-GK berada dalam kategori Baik.

\section{Faktor Akreditasi}

Hasil pengolahan data, diketahui variabel Akreditasi pada STAI memiliki nilai rata-rata indeks sebesar 3,41 sedangkan nilai indeks rata-rata untuk STIE-GK untuk variabel yang sama, adalah sebesar 3,44. Yang menunjukan bahwa mahasiswa berpendapat bahwa Status Akreditasi pada STAI dan STIE-GK berada dalam kategori Baik.

\section{Faktor Fasilitas}

Hasil pengolahan data, diketahui variabel Fasilitas yang dimiliki oleh STAI memiliki nilai ratarata indeks sebesar 3,42, sedangkan STIE-GK sebesar 3,47. Yang menunjukan bahwa mahasiswa berpendapat bahwa Fasilitas yang ada STAI dan STIE-GK berada dalam kategori Baik.

\section{Faktor Biaya}

Hasil pengolahan data, diketahui variabel Biaya pada STAI memiliki nilai rata-rata indeks sebesar 3,41, sedangkan STIE-GK sebesar 3,50. Yang menunjukan bahwa Biaya yang ditetapkan oleh STAI dan STIE-GK berada dalam kategori Baik atau masih tergolong murah.

\section{Keputusan Siswa}

Pengolahan data, diketahui variabel Keputusan Siswa untuk masuk STAI memiliki nilai ratarata indeks sebesar 3,42, sedangkan STIE-GK sebesar 3,47. Yang menunjukan bahwa keputusan siswa untuk masuk STAI maupun STIE-GK Muara Bulian berada dalam kategori Baik.

\section{Analisis Faktor-Faktor Yang Mempengaruhi Siswa dalam memilih perguruan tinggi di Kabupaten Batang Hari. Uji Validitas}

Berdasarkan perhitungan dengan SPSS 20, diketahui bahwa keseluruhan nilai $\mathrm{r}$ hitung $>$ $\mathrm{r}_{\text {tabel }}(\mathrm{df}=\mathrm{n}=75)$ maka dapat dikatakan semua keseluruhan pertanyaan dinyatakan valid untuk digunakan dalam penelitian ini, baik item pertanyaan untuk STAI maupun STIE-GK Muara Bulian.

\section{Uji Reliabilitas}


Faktor-Faktor yang Mempengaruh Siswa SLTA dalam Memilih Perguruan Tinggi di Kabupaten Batang Hari (Studi Kasus Pada STAI dan STIE-GK Muara Bulian)

Berdasarkan perhitungan dengan SPSS 20, diketahui bahwa masing-masing indikator yang digunakan, mempunyai nilai Cronbach Alpha (a) lebih besar dari 0,6. Hal ini menunjukan keseluruhan variabel penelitian dapat dinyatakan reliable (tangguh) untuk digunakan pada analisa selanjutnya.

\section{Analisis Regresi Linear Berganda}

Tabel 2. Hasil Regresi Linear Berganda untuk STAI Muara Bulian

\begin{tabular}{|c|c|c|c|c|c|c|}
\hline \multirow{2}{*}{\multicolumn{2}{|c|}{ Model }} & \multicolumn{2}{|c|}{ Unstandardized Coefficients } & \multirow{2}{*}{\begin{tabular}{|c|} 
Standardized Coefficients \\
Beta
\end{tabular}} & \multirow[t]{2}{*}{$\mathrm{t}$} & \multirow[t]{2}{*}{ Sig. } \\
\hline & & B & Std. Error & & & \\
\hline \multirow{5}{*}{1} & (Constant) & ,203 & ,782 & & ,259 & ,797 \\
\hline & Program_Studi & ,018 & 208 & ,0 & ,086 & ,932 \\
\hline & Akreditasi & , 450 & ,224 & ,4 & 2,011 &, 052 \\
\hline & Fasilitas & ,217 & ,248 & ,2 & ,874 & ,388 \\
\hline & Biaya & 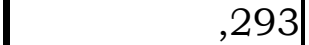 & 207 & & 1,417 & , 165 \\
\hline
\end{tabular}

Sumber: data olahan

$\mathrm{Y}=0,203+0,018 \mathrm{X}_{1}+0,450 \mathrm{X}_{2}+0,217 \mathrm{X}_{3}+0,293 \mathrm{X}_{4}$

Interpretasi dari persamaan regresi diatas adalah sebagai berikut:

1. Ini berarti jika semua variabel independen (program studi, akreditasi, fasilitas dan biaya) memiliki nilai nol, maka nilai variabel dependen (keputusan siswa untuk masuk STAI Muara Bulian) sebesar 0,203.

2. Faktor Program Studi $\left(\mathrm{X}_{1}\right)$ Terhadap keputusan siswa $(\mathrm{Y})=0,018$

Nilai koefisien untuk variabel Program Studi $\left(\mathrm{X}_{1}\right)$ sebesar 0,018 dan bertanda positif, ini menunjukkan bahwa setiap kenaikan satu satuan variabel program studi. maka variabel keputusan siswa untuk masuk STAI Muara Bulian (Y) akan meningkat sebesar 0,018 dengan asumsi bahwa variabel dependen yang lain dari model regresi adalah tetap.

3. Faktor Akreditasi $\left(\mathrm{X}_{2}\right)$ terhadap keputusan siswa $(\mathrm{Y})=0,450$

Nilai koefisien untuk variabel factor Akreditasi $\left(\mathrm{X}_{2}\right)$ sebesar 0,450 dan bertanda positif, ini menunjukkan bahwa setiap kenaikan satu satuan variabel akreditasi, maka variabel keputusan siswa untuk masuk STAI Muara Bulian (Y) akan meningkat sebesar 0,450 dengan asumsi bahwa variabel dependen yang lain dari model regresi adalah tetap.

4. Factor fasilitas $\left(\mathrm{X}_{3}\right)$ terhadap keputusan siswa $(\mathrm{Y})=0,217$

Nilai koefisien untuk variabel faktor fasilitas $\left(\mathrm{X}_{3}\right)$ sebesar 0,217 dan betanda positif, ini menunjukkan bahwa setiap kenaikkan satu satuan variabel fasilitas, maka variabel keputusan siswa untuk masuk STAI Muara Bulian (Y) akan meningkat sebesar 0,217 dengan asumsi bahwa variabel dependen yg lain dari model regresi adalah tetap.

5. Faktor Biaya $\left(\mathrm{X}_{4}\right)$ terhadap keputusan siswa $(\mathrm{Y})=0,293$

Nilai koefisien untuk variabel factor biaya $\left(\mathrm{X}_{4}\right)$ sebesar 0,293 dan bertanda positif, ini menunjukkan bahwa setiap kenaikan satu satuan variabel harga, maka variabel keputusan siswa untuk masuk STAI Muara Bulian (Y) akan meningkat sebesar 0,293 dengan asumsi bahwa variabel dependen yg lain dari model regresi adalah tetap.

Tabel 3. Hasil Regresi Linear Berganda untuk STIE-GK Muara Bulian

\begin{tabular}{|c|c|c|c|c|c|c|c|}
\hline \multirow{2}{*}{\multicolumn{2}{|c|}{ Model }} & \multicolumn{2}{|c|}{ Unstandardized Coefficients } & \multirow{2}{*}{\multicolumn{2}{|c|}{$\frac{\text { Standardized Coefficients }}{\text { Beta }}$}} & \multirow[t]{2}{*}{$\mathrm{t}$} & \multirow[t]{2}{*}{ Sig. } \\
\hline & & $\mathrm{B}$ & Std. Error & & & & \\
\hline \multirow{5}{*}{1} & $\overline{(\text { Constant) }}$ & ,610 & $\overline{547}$ & & & 1,115 & 269 \\
\hline & Program_Studi & ,431 & 137 & & 307 & 3,144 & ,002 \\
\hline & Akreditasi & ,232 & 097 & &, 164 & 2,387 &, 020 \\
\hline & Fasilitas & ,442 & 095 & & 289 & 4,662 & 000 \\
\hline & Biaya & ,365 & 085 & & 262 & 4,291 & 000 \\
\hline
\end{tabular}

Sumber: data olahan 
Faktor-Faktor yang Mempengaruh Siswa SLTA dalam Memilih Perguruan Tinggi di Kabupaten Batang Hari (Studi Kasus Pada STAI dan STIE-GK Muara Bulian)

$\mathrm{Y}=0,610+0,431 \mathrm{X}_{1}+0,232 \mathrm{X}_{2}+0,442 \mathrm{X}_{3}+0,365 \mathrm{X}_{4}$

Interpretasi dari persamaan regresi diatas adalah sebagai berikut:

1. Ini berarti jika semua variabel independen (program studi, akreditasi, fasilitas dan biaya) memiliki nilai nol, maka nilai variabel dependen (keputusan siswa untuk masuk STIE-GK Muara Bulian) sebesar 0,610.

2. Faktor Program Studi $\left(\mathrm{X}_{1}\right)$ Terhadap keputusan siswa $(\mathrm{Y})=0,431$

Nilai koefisien untuk variabel Program Studi $\left(\mathrm{X}_{1}\right)$ sebesar 0,431 dan bertanda positif, ini menunjukkan bahwa setiap kenaikan satu satuan variabel program studi. maka variabel keputusan siswa untuk masuk STIE-GK Muara Bulian (Y) akan meningkat sebesar 0,431 dengan asumsi bahwa variabel dependen yang lain dari model regresi adalah tetap.

3. Faktor Akreditasi $\left(\mathrm{X}_{2}\right)$ terhadap keputusan siswa $(\mathrm{Y})=0,232$

Nilai koefisien untuk variabel factor Akreditasi $\left(\mathrm{X}_{2}\right)$ sebesar 0,232 dan bertanda positif, ini menunjukkan bahwa setiap kenaikan satu satuan variabel akreditasi, maka variabel keputusan siswa untuk masuk STIE-GK Muara Bulian (Y) akan meningkat sebesar 0,232 dengan asumsi bahwa variabel dependen yang lain dari model regresi adalah tetap.

4. Factor fasilitas $\left(\mathrm{X}_{3}\right)$ terhadap keputusan siswa $(\mathrm{Y})=0,442$

Nilai koefisien untuk variabel faktor fasilitas $\left(\mathrm{X}_{3}\right)$ sebesar 0,442 dan betanda positif, ini menunjukkan bahwa setiap kenaikkan satu satuan variabel fasilitas, maka variabel keputusan siswa untuk masuk STIE-GK Muara Bulian (Y) akan meningkat sebesar 0,442 dengan asumsi bahwa variabel dependen yg lain dari model regresi adalah tetap.

5. Faktor Biaya $\left(\mathrm{X}_{4}\right)$ terhadap keputusan siswa $(\mathrm{Y})=0,365$

Nilai koefisien untuk variabel factor biaya $\left(\mathrm{X}_{4}\right)$ sebesar 0,365 dan bertanda positif, ini menunjukkan bahwa setiap kenaikan satu satuan variabel harga, maka variabel keputusan siswa untuk masuk STIE-GK Muara Bulian (Y) akan meningkat sebesar 0,365 dengan asumsi bahwa variabel dependen yg lain dari model regresi adalah tetap.

\section{Uji $t$ (Uji Parsial)}

Uji $\mathrm{t}$ dimaksudkan untuk melihat secara parsial variabel dependen (program studi, Akreditasi, fasilitas, dan biaya) berpengaruh terhadap keputusan siswa dalam memilih perguruan tinggi. Adapun signifikasi dari masing-masing koefisien itu diuji dengan menggunakan uji parsial t-test yang tampak pada Tabel 1 dan 2 diatas dapat dijelaskan sebagai berikut:

\section{STAI Muara Bulian.}

a. Untuk Program Studi $\left(\mathrm{X}_{1}\right)$, angka $t_{\text {hitung }}$ sebesar 0,086 lebih kecil dari angka $t_{\text {tabel }}(\mathrm{df}=75-4-1$ $=70$ ) sebesar 1,66691 dan angka signifikasi sebesar 0,932 lebih besar dari angka level of significacnce 0,05. Dapat disimpulkan bahwa variabel program studi tidak berpengaruh secara pasial dan signifikan terhadap keputusan siswa untuk masuk STAI Muara Bulian.

b. Untuk faktor Akreditasi $\left(\mathrm{X}_{2}\right)$, angka $t_{\text {hitung }}$ sebesar 2.011 lebih besar dari angka $t_{\text {tabel }} 1,66691$ dan angka signifikasi sebesar 0,052 lebih besar dari angka level of significance 0,05. Dapat disimpulkan bahwa variabel akreditasi berpengaruh secara parsial terhadap keputusan siswa untuk masuk STAI Muara Bulian, akan tetapi tidak signifikan.

c. Untuk faktor fasilitas $\left(\mathrm{X}_{3}\right)$, angka $t_{\text {hitung }}$ sebesar 0,874 lebih kecil dari angka $t_{\text {tabel }} 1,66691$ dengan angka signifikasi sebesar 0,388 lebih besar dari angka level of significance 0,05. Dapat disimpulkan bahwa variabel fasilitas tidak mempunyai pengaruh secara parsial dan tidak signifikan terhadap keputusan siswa untuk masuk STAI Muara Bulian.

d. Untuk faktor Biaya $\left(\mathrm{X}_{4}\right)$, angka thitung sebesar 1,417 lebih kecil dari angka tabel 1,66691 dengan angka signifikasi sebesar 0,165 lebih besar dari angka level of significance 0,05. Dapat disimpulkan bahwa variabel Biaya tidak mempunyai pengaruh secara parsial dan tidak signifikan terhadap keputusan siswa untuk masuk STAI Muara Bulian.

\section{STIE-GK Muara Bulian.}

a. a. Untuk Program Studi $\left(\mathrm{X}_{1}\right)$, angka $t_{\text {hitung }}$ sebesar 3,144 lebih besar dari angka $t_{\text {tabel }} \quad(\mathrm{df}=$ $\mathrm{n}-\mathrm{k}-1)$ sebesar 1,66691 dan angka signifikasi sebesar 0,002 lebih kecil dari angka level of significacnce 0,05. Dapat disimpulkan bahwa variabel program studi tidak berpengaruh 
Faktor-Faktor yang Mempengaruh Siswa SLTA dalam Memilih Perguruan Tinggi di Kabupaten Batang Hari (Studi Kasus Pada STAI dan STIE-GK Muara Bulian)

secara pasial dan signifikan terhadap keputusan siswa untuk masuk STIE-GK Muara Bulian.

b. Untuk faktor Akreditasi $\left(\mathrm{X}_{2}\right)$, angka $t_{\text {hitung }}$ sebesar 2.387 lebih besar dari angka $t_{\text {tabel }} 1,66691$ dan angka signifikasi sebesar 0,020 lebih kecil dari angka level of significance 0,05. Dapat disimpulkan bahwa variabel akreditasi berpengaruh secara parsial dan signifikan terhadap keputusan siswa untuk masuk STIE-GK Muara Bulian.

c. Untuk faktor fasilitas $\left(\mathrm{X}_{3}\right)$, angka thitung sebesar 4,662 lebih besar dari angka tabel 1,66691 dan dengan angka signifikasi sebesar 0,000 lebih kecil dari angka level of significance 0,05. Dapat disimpulkan bahwa variabel fasilitas mempunyai pengaruh secara parsial dan signifikan terhadap keputusan siswa untuk masuk STIE-GK Muara Bulian.

d. Untuk faktor Biaya $\left(\mathrm{X}_{4}\right)$, angka thitung sebesar 4,291 lebih besar dari angka tabel 1,66691 dengan angka signifikasi sebesar 0,000 lebih kecil dari angka level of significance 0,05. Dapat disimpulkan bahwa variabel Biaya mempunyai pengaruh secara parsial dan signifikan terhadap keputusan siswa untuk masuk STIE-GK Muara Bulian.

\section{Uji F (Simultan)}

Tabel 4. Koefisien Regresi untuk STAI Muara Bulian

\begin{tabular}{|ll|r|r|r|r|r|}
\hline Model & & Sum of Squares & df & Mean Square & F & Sig. \\
\hline \multirow{2}{*}{1} & Regression & 139,978 & 4 & 34,995 & 76,972 &, $000^{\mathrm{b}}$ \\
& Residual & 15,458 & 70 &, 455 & & \\
& Total & 155,436 & 75 & & & \\
\hline
\end{tabular}

Sumber: data olahan

Hasil perhitungan statistic uji $\mathrm{F}$ pada Tabel 4 diatas, diperoleh nilai $\mathrm{f}_{\text {hitung }}$ adalah 76,972 dengan nilai signifikan 0,000 lebih kecil dari tingkat signifikan 0,05 dan nilai $\mathrm{f}_{\text {tabel }}(\mathrm{df}=\mathrm{n}-\mathrm{k}-1)$ sebesar 2,50. (nilai $f_{\text {hitung }}>$ dari $f_{\text {tabel). Artinya secara bersama- sama variabel indefendent }}$ (program studi, akreditasi, fasilitas dan biaya) berpengaruh secara signifikan terhadap variabel defendant (keputusan siswa) siswa untuk masuk STAI Muara Bulian.

Tabel 5. Koefisien Regresi untuk STIE-GK Muara Bulian

\begin{tabular}{|ll|l|l|l|l|l|}
\hline Model & & Sum of Squares & df & Mean Square & F & Sig. \\
\hline \multirow{2}{*}{1} & Regression & 1662,912 & 4 & 165,728 & 384,348 &, $000^{\mathrm{b}}$ \\
& Residual & 30,615 & 70 &, 431 & & \\
& Total & 693,526 & 75 & & & \\
\hline
\end{tabular}

Sumber: data olahan

Hasil perhitungan statistic uji $\mathrm{F}$ pada tabel 5 diatas, diperoleh nilai $\mathrm{f}_{\text {hitung }}$ adalah 384,348 dengan nilai signifikan 0,000 lebih kecil dari tingkat signifikan 0,05 dan nilai $\mathrm{f}_{\text {tabel }}(\mathrm{df}=\mathrm{n}-\mathrm{k}-1=$

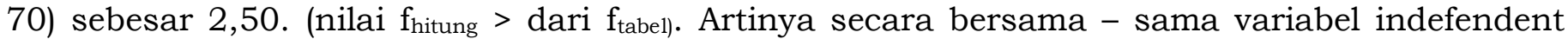
(program studi, akreditasi, fasilitas dan biaya) berpengaruh secara signifikan terhadap variabel defenden (keputusan) siswa untuk masuk STIE-GK Muara Bulian.

\section{Analisis Koefisien Determinasi $\left(R^{2}\right)$}

Tabel 6. Pengujian R Square untuk STAI Muara Bulian

\begin{tabular}{|r|r|r|r|r|}
\hline \multicolumn{1}{|c|}{ Model } & R & R Square & Adjusted R Square & Std. Error of the Estimate \\
\hline 1 &, 949 &, 901 &, 889 &, 67427 \\
\hline
\end{tabular}

Sumber: data olahan 
Hasil analisis diperoleh nilai adjusted $\mathrm{R}$ square, sebesar 0,889 hal ini menunjukan bahwa variabel independen (Program Studi, Akreditasi, Fasilitas dan Biaya) memberikan kontribusi terhadap variabel dependen ( keputusan siswa) sebesar 88,9 \% untuk masuk STAI Muara Bulian dan sisanya sebesar 0,111 atau $11,1 \%$ dipengaruhi oleh variabel lain yang tidak termasuk dalam penelitian ini.

Tabel 7. Pengujian R Square untuk STIE-GK Muara Bulian

\begin{tabular}{|c|l|l|l|l|}
\hline \multicolumn{1}{|c|}{ Model } & \multicolumn{1}{c|}{$\mathrm{R}$} & \multicolumn{1}{c|}{ R Square } & Adjusted R Square & Std. Error of the Estimate \\
\hline 1 &, $978^{\mathrm{a}}$ &, 956 &, 953 &, 65665 \\
\hline
\end{tabular}

Sumber: data olahan

Hasil analisis diperoleh nilai adjusted $\mathrm{R}$ square, sebesar 0,953 hal ini menunjukan bahwa variabel independen (Program Studi, Akreditasi, Fasilitas dan Biaya) memberikan kontribusi terhadap variabel dependen (keputusan siswa) sebesar 95,3\% untuk masuk STIE-GK Muara Bulian dan sisanya sebesar 0,047 atau 4,7 \% dipengaruhi oleh variabel lain yang tidak termasuk dalam penelitian ini.

\section{SIMPULAN}

Berdasarkan hasil penelitian dan pembahasan maka dapat diperoleh beberapa kesimpulan sebagai berikut:

1. Program studi $\left(\mathrm{X}_{1}\right)$ pada STAI Muara Bulian termasuk dalam kategori Cukup Baik sementara program studi pada STIE-GK masuk dalam kategori Baik; mengenai status Akreditasi $\left(\mathrm{X}_{2}\right)$, Fasilitas $\left(\mathrm{X}_{3}\right)$, beban Biaya $\left(\mathrm{X}_{4}\right)$ dan Keputusan Siswa dalam memilih perguruan tinggi pada STAI dan STIE-GK Muara Bulian termasuk sama-sama dalam kategori Baik

2. Hasil analisa dengan menggunakan uji t, uji $\mathrm{F}$ dan uji $\mathrm{R}^{2}$ (koefosien determinasi), didapat hasil untuk STAI Muara Bulian bahwa program studi, fasilitas dan biaya tidak berpengaruh secara parsial dan tidak signifikan terhadap keputusan siswa, dan Akreditasi berpengaruh terhadap keputusan siswa untuk masuk ke STAI Muara Bulian tetapi tidak signifikan. sedangkan untuk STIE-GK Muara Bulian diketahui program studi, akreditasi, fasilitas dan biaya berpengaruh secara parsial dan signifikan terhadap keputusan siswa. Uji $\mathrm{F}$ diketahui bahwa program studi, akreditasi, fasilitas dan biaya secara signifikan berpengaruh terhadap keputusan siswa untuk masuk STAI maupun STIE-GK Muara Bulian. Sedangkan dilihat dari persentase, keseluruhan faktor memberikan kontribusi terhadap keputusan siswa untuk masuk STAI Muara Bulian sebesar 88,9 \% dan 95,3 \% untuk masuk STIE-GK Muara Bulian dan sisanya masing-masing sebesar $11,1 \%$ dan $4,7 \%$ dipengaruhi oleh faktor lain yang tidak termasuk dalam variabel penelitian.

\section{DAFTAR PUSTAKA}

Adisetiawan, R., 2016, Faktor yang Mempengaruhi Lulusan SMA dalam Memilih Fakultas Ekonomi Program Studi Manajemen Universitas Batanghari, Jurnal Ilmiah Universitas Batanghari Jambi, 16(3), 1-11

Adisetiawan, R., 2017, Performance Mahasiswa Fakultas Ekonomi Universitas Batanghari, Jurnal Ilmiah Universitas Batanghari Jambi, 14(3), 1-10

Ghozali, Imam. 2011, Aplikasi Analisis Multivariat dengan Program SPSS, Badan Penerbit Universitas Diponegoro, Semarang.

Sugiyono. 2011. Metode Penelitian Kuantitatif, Kualitatif dan R\&D. Bandung: Alfabeta. 